\title{
Participatory Microbiome Research With Hmong and Karen Communities: Lessons Learned
}

\author{
Pajau Vangay ${ }^{1}$,, Nancy Yang ${ }^{2}$, Shannon Pergament ${ }^{3}$, Mary Xiong ${ }^{3}$, Bwei Paw ${ }^{3}$, Rodolfo Batres ${ }^{3}$, Dan Knights ${ }^{4}$, Kathleen A. \\ Culhane-Pera $^{5}$ \\ ${ }^{1}$ Bioinformatics and Computational Biology, University of Minnesota, ${ }^{2}$ School of Medicine, University of Minnesota, ${ }^{3}$ Somali, Latino and Hmong Partnership for \\ Health and Wellness, Community-University Health Care Center, ${ }^{4}$ Computer Science and Engineering, Biotechnology Institute, University of Minnesota, 5 \\ Somali, Latino and Hmong Partnership for Health and Wellness, Community-University Health Care Center, and Minnesota Community Care \\ Keywords: microbiome, obesity, immigrant, refugee, community-based participatory research, Hmong, Karen \\ https://doi.org/10.35844/001c.29669
}

Journal of Participatory Research Methods

Vol. 2, Issue 3, 2021

In this brief report, we share lessons learned from the Immigrant Microbiome Project (IMP), a microbiome research study conducted in partnership with the Hmong and Karen communities in Minnesota. Members of the IMP academiccommunity research team and community advisory board reflected on the community-based participatory research (CBPR) approach used for the IMP project, which informed these lessons learned. The IMP illustrates how microbiome researchers can utilize CBPR, which can improve the validity of research projects, create respectful partnerships, build trust between community members and researchers, and ensure that research results are returned to the community as actions that can improve health.

\section{Introduction}

Research about the human gut microbiome (microbial community in the intestinal tract) has revealed profound differences between populations (Fragiadakis et al., 2019; Smits et al., 2017; Vangay et al., 2018; Yatsunenko et al., 2012). A number of microbiome studies have now shown that people in highly industrialized societies tend to have fewer types of intestinal microbes than people living in non-industrialized societies (Smits et al., 2017). Other studies have linked migration to highly industrialized countries, including the United States (U.S.), with increased risk of microbiome-related diseases, like obesity and diabetes (Goel et al., 2004; Heney et al., 2014; Lauderdale \& Rathouz, 2000). The U.S. hosts the largest number of immigrants in the world (Department of Economic and Social Affairs, Population Division, 2017), and epidemiological evidence has shown that residency in the U.S. increases the risk of obesity among immigrants, with some groups experiencing up to a four-fold increase in risk after 15 years (Bates et al., 2008; Cairney \& Østbye, 1999; Goel et al., 2004; Kaplan et al., 2004; Lauderdale \& Rathouz, 2000; Walker et al., 2008). This so-called "healthy immigrant effect" has been welldocumented in Western countries (Antecol \& Bedard, 2006), and is attributed to many complex, interacting factors with varying effects that are dependent upon the subpopulation (Barcenas et al., 2007). Refugees, in particular, appear to be more vulnerable to rapid weight gain (Heney et al., 2014; Hervey et al., 2009) compared to immigrants, with Southeast Asian refugees exhibiting the highest average increases in Body Mass Index (BMI) (Careyva et al., 2015) after relocation to the U.S. We hypothesized that the human gut microbiome, due to its important role in human health, was one of many complex factors 
that contribute to the "healthy immigrant effect." We started the Immigrant Microbiome Project (IMP) to test the hypothesis that relocating to the U.S. would induce changes in the human gut microbiome, and that these gut microbial changes would contribute to the development of obesity.

During the early planning stages of the IMP, we prioritized working on health issues that were prevalent in, but also deemed important by, our local communities in Minnesota. This required us to engage with and learn about our diverse communities, which included discovering that Minnesota was home to the highest number of refugees per capita in the U.S. (Koumpilova, 2015). Our desire to work on health issues that were important to our local refugee communities ultimately defined the communities as core stakeholders in our project. This, combined with our need to understand and overcome the important ethical challenges (Jacobsen \& Landau, 2003; Murray et al., 2010; Temple \& Moran, 2006) in working with refugee populations, prompted us to look toward community-based participatory research (CBPR).

Conventional research on marginalized populations has not historically been organized to specifically ensure benefits to the communities being studied (Tuck \& Yang, 2014). CBPR engages with the studied communities in every step of the research process, including sharing power and ownership of the research equitably between researchers and the community members (Viswanathan et al., 2004), thereby resulting in improved research validity (Jagosh et al., 2012; Viswanathan et al., 2004). CBPR has been applied extensively in epidemiological and clinical studies (Israel et al., 2010; Leung et al., 2004), and only recently has been considered in genomic research studies (Buseh et al., 2013; Claw et al., 2018; Skinner et al., 2015).

CBPR fundamentally changed our approach to scientific research about the human microbiome and was key to our project's success. In this brief report, we describe how we carried out our research activities in partnership with the Hmong and Karen communities in Minnesota and share our lessons learned in hopes of encouraging microbiome scientists to consider this inclusive and equitable approach.

\section{Historical context on the Hmong and Karen communities in the U.S.}

The Hmong and Karen communities share experiences as refugees from Southeast Asia, but came to the U.S. at distinct times due to different historical events. During the 1960s-1970s, the U.S. recruited Hmong people to fight in a CIA-sponsored U.S. Secret War in Laos (Michaud \& Hamilton-Merritt, 1994). Afterward, the Hmong faced harsh retribution for aiding the U.S. and began fleeing to Thailand in 1975. Between 1976-1990 and 2004-2005, about 90 percent of all Hmong refugees in Thailand were resettled to the U.S. (U.S. Department of Homeland Security, 2011), and as a result, more than 100,000 foreign-born Hmong reside in the U.S. today (Pfeifer et al., 2012). The Karen people are an ethnic minority from Myanmar (Burma) who, since the mid-1940s, have been in conflict with the Myanmar government for independence (Kuroiwa \& Verkuyten, 2008; Walton, 2008). In 1984, the Karen began entering Thailand as refugees (B.E.R. Group \& Friedrich- 
Naumann-Stiftung, 1998; The Border Consortium, n.d.). From 2000-2017, more than 170,000 Burmese refugees of primarily Karen ethnicity were resettled to the U.S. (Mossaad, 2019), with many originating from Mae La camp, the largest refugee camp in Thailand (The Border Consortium, 2018). The prevalence of overweight and obesity is highest among Hmong compared to other Asian ethnic groups (Arcan et al., 2014; Franzen \& Smith, 2009; Himes et al., 1992; Mulasi-Pokhriyal et al., 2012), with Western diet acculturation, previous exposure to food insecurity, and physical inactivity identified as contributing factors (Franzen \& Smith, 2009; Mulasi-Pokhriyal et al., 2012; C. Smith \& Franzen-Castle, 2012). Refugee children from Burma exhibited the steepest BMI increase after relocation compared with other refugee and non-refugee children (Dawson-Hahn et al., 2016); to our knowledge, disaggregated data for refugees of Karen ethnicity from Burma does not yet exist.

\section{Methods}

\section{Partnership formation}

In 2014, academic researchers from the University of Minnesota (UMN) and community researchers from Somali, Latino and Hmong Partnership for Health and Wellness (SoLaHmo) (the "academic-community research team") initiated conversations for implementation of a CBPR approach for the IMP (Table 1, Figure 1). After collaborating to develop grant proposals and successfully obtaining funding support in 2015, the academic-community research team expanded to include two Hmong researchers and one Karen community researcher. The academic-community research team was trained by SoLaHmo staff using training materials built upon key CBPR principles in the Community-Based Participatory Action Research Partnership Protocol (SoLaHmo Partnership for Health \& Wellness at West Side Community Health Services, Inc. \& University of Minnesota's Program in Health Disparities Research Advisory Board, 2017). The academic-community research team began actively partnering with Hmong and Karen community members via community advisory boards (CABs), who provided asynchronous feedback on research materials via email, as well as live feedback during three in-person group meetings (start of recruitment, during recruitment, and prior to dissemination of results) (Table 1). All research materials were reviewed and approved by the academic-community research team and CABs.

\section{Scientific research study design}

From 2016-2017, the IMP enrolled 550 Hmong and Karen women in Minnesota and Thailand and collected stool samples for gut microbiome analysis. A longitudinal sub-study was conducted, which included analysis of monthly stool samples collected from Karen women during their first six months of living in Minnesota. The main research study included analysis of stool samples collected from Hmong and Karen women in the U.S. at a single point in time and accounted for factors such as diet, age, and time 
3 academic researchers

9 Hmong $\mathrm{CAB}$

members

2 SoLaHmo staff researchers

2 Hmong community researchers

1 Karen community researcher

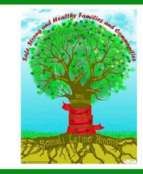

6 Karen CAB

members

Figure 1.

Our academic-community research team consisted of three academic researchers from UMN (PV, DK, NY), three staff community researchers from SoLaHmo (KACP, SLP, RB), two Hmong community researchers (MX, PS), and one Karen community researcher (BP). The CABs consisted of nine Hmong and six Karen members. A subset of the research team participated in this reflection (three UMN researchers, two SoLaHmo researchers, one Hmong community researcher, four Hmong CAB members, one Karen community researcher, one Karen $\mathrm{CAB}$ member). Note that part of the research study was conducted in Thailand, where we partnered with academic and community researchers on CBPR training, co-authoring the scientific manuscript, and dissemination of study results and materials. Unfortunately, we were unable to implement all of the CBPR key principles in Thailand due to geographical, time, funding, and logistical constraints. Thus, our Thailand partners are not included in this reflection.

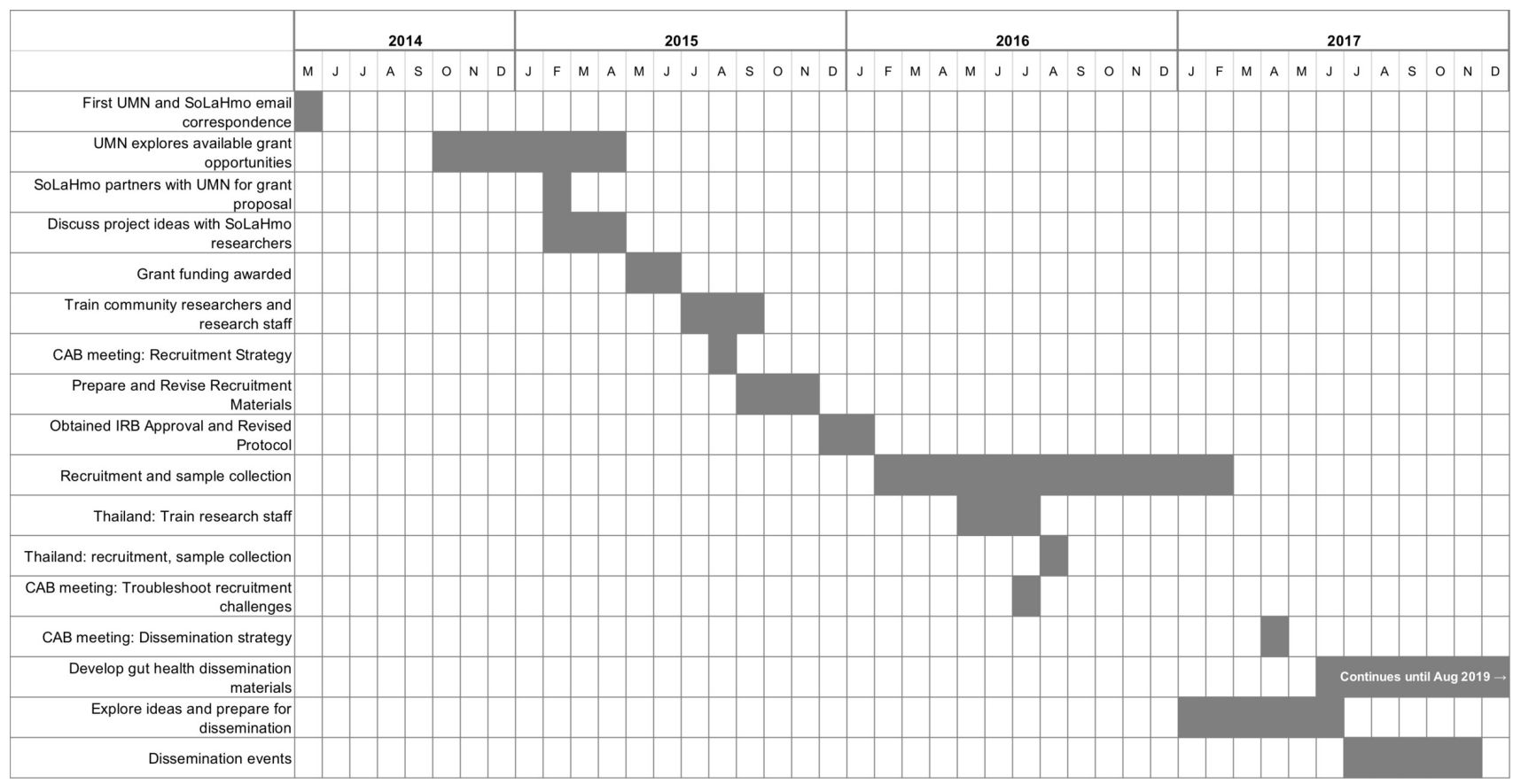

Table 1. Timeline of the research study.

spent in the U.S. Stool samples were also collected from Hmong and Karen women in Thailand to determine a baseline representation of gut microbiome composition prior to relocation.

\section{Recruitment and enrollment of participants}

From 2016-2017, we recruited and enrolled Hmong and Karen participants throughout the greater Twin Cities area in Minnesota at multiple locations, including adult education centers, cultural centers, religious organizations, 
clinics, and individuals' homes. Community researchers presented the research study's goals and objectives, explained sample collection methods, and obtained informed consent individually or in groups. After signing the consent form, participants were interviewed about their diet (24-hour recall), demographics, and socioeconomic situation; had height, weight, and waist circumference measured; and received a self-sampling stool collection kit. Stool samples were returned by mail or picked up by the academic-community research team, and upon receipt, participants received a $\$ 20$ prepaid credit card.

\section{Research results}

We found that gut microbiomes changed quickly after relocation and that these changes were correlated with obesity risk, which increased with time in the U.S. (Vangay et al., 2018). We found that the diets of our participants changed more slowly than their gut microbiomes over time in the U.S., indicating that other non-dietary factors contributed to these gut microbial changes.

\section{Community team reflections}

To identify "lessons learned," one research team member led three in-person discussions with the academic-community team and several $\mathrm{CAB}$ members to reflect upon and review the research study through the framework of CBPR principles from the SoLaHmo-UMN Partnership Protocol (SoLaHmo Partnership for Health \& Wellness at West Side Community Health Services, Inc. \& University of Minnesota's Program in Health Disparities Research Advisory Board, 2017). The academic-community research team analyzed the notes, which were then shared with the community researchers and $C A B$ members for additional input.

\section{Lessons Learned}

\section{Planning Stage}

\section{Engage with the Community Before Starting Any Research Study}

Initially, we conducted discussions with members of several immigrant and refugee communities, as we wanted our research project to focus on a health issue that was a concern for these communities as well as be scientifically interesting and relevant for gut microbiome research. Members of these communities reported being concerned about developing obesity and chronic diseases like diabetes and hypertension after moving to the U.S. While some community members were aware of contributing factors to obesity such as changes in diet, exercise, and lifestyle, the role of the gut microbiome was a new concept and they were curious to learn more. While we considered partnering with several different ethnic communities and health topics, we decided to move forward with the Hmong and Karen communities and the topic of obesity based on community interest and availability of community researchers. These early conversations ensured interest and commitment from the communities and helped frame important prerequisite activities, such as grant-proposal writing. 


\section{Develop a Collaborative Agreement}

Once we identified the health topic and interested Hmong and Karen community members, we began building a partnership. We trained all the researchers on the Hmong and Karen communities, CBPR, research ethics, and the gut microbiome. We developed a collaborative agreement, which entailed: clear individual roles and responsibilities; consensus-based decisionmaking; open communication and conflict resolution; and a commitment to disseminate findings to the Hmong and Karen communities and to academia, with co-authorship (Office of Academic Clinical Affairs, 2018). Throughout the project, we aimed for equitable team dynamics. During our final reflection, community researchers stated they felt respected for their expertise in working with the community, as academic researchers relied heavily on them to create effective processes, develop trustworthy connections, and address challenges in enrollment. In turn, the community researchers trusted the academic researchers to champion the communities' perspectives, and to address their concerns efficiently and collaboratively. Importantly, our CBPR team was strengthened because we had an academic researcher who is also a member of one partner community, and hence had a valuable role in balancing both the scientific and community perspectives for the project.

\section{Study Design}

\section{Respect that Refugees Have Historical Experiences and Concerns About Research}

The Hmong and Karen communities shared their perceptions about research, which were strongly shaped by the communities' past experiences. Some Hmong participants initially questioned the research teams' intentions and shared their concerns about breaches of confidentiality and privacy, as well as possible adverse retributions based on research results. Trust was particularly important for community members; therefore, having community researchers who were well-connected in the community or who have been endorsed by people who participants trusted was a critical first step. For example, recruitment via flyers or public booths were not successful compared with recruitment through an established network (such as a religious organization) and individual referrals.

$\mid$

"...people sometimes think [UMN is] related to the CIA. A lot of people from Thailand had trauma with the [U.S.] government..." (Hmong CAB Member)

"We talked a lot about how the community interpreted poop, and fear of personal information being shared, and giving their own samples as a fear of getting detected if they were ill in other areas..." (Hmong Community Researcher)

In contrast, Karen participants reported positive experiences with researchers, primarily Mae La refugee camp's action-oriented research projects related to malaria and maternal health (The Border Consortium, 2018), and 
thus were more open to participating in the research study. Our Karen researcher was also well-connected and a long-time champion of his community, which was integral for establishing trust.

"Most people said yes [to participating in the study] because I used [the research project in Thailand] as an example, which they did back at the camp." (Karen Community Researcher)

\section{Obtain Culturally-and Linguistically-Appropriate Informed Consent}

Understanding the Hmong and Karen histories prior to arriving in the U.S. provided important insights into effective communication and engagement strategies with these communities. Having been in the U.S. for vastly different amounts of time, the two communities had differences in English language acquisition, degree of acculturation to the U.S., and preferred communication strategies. It was important that our community researchers spoke fluent Hmong and Karen so that they could effectively address participants' questions and concerns. Perhaps more importantly, our team prioritized the communities and took community feedback seriously, even as it required additional rounds of protocol revisions with the team, preparing amendments to our IRB protocol, and delays while waiting for IRB approval. By the end of the project, we had used a multi-pronged approach that had provided participants with culturally- and linguistically-appropriate informed consent by offering: written and verbal explanations in Hmong and Karen; visual aids explaining the project; accessible, familiar, and trusted meeting locations; and opportunities for discussion with community peers.

\section{Ensure Shared Decision-Making Throughout All Phases of the Study}

The academic-community research team shared decision-making about study design, recruitment and consent methods, sample collection, results interpretation, and dissemination. Each phase included the academiccommunity researchers and $\mathrm{CAB}$ members in rigorous iterations of revisions. For instance, after $\mathrm{CAB}$ discussions identified that recent Hmong arrivals from Southeast Asia were mostly women, the study design was modified to only include women. Similarly, we abandoned scientific research plans for a randomized control trial to evaluate how inulin fiber ingestion affects the microbiome, due to $\mathrm{CAB}$ concerns about the abortifacient potential of inulin/ chicory root fiber (Ernst, 2002). Instead, we added a controlled dietary intervention experiment in mice that allowed us to test a similar scientific hypothesis while respecting the perspectives and concerns of the community.

Recruitment and enrollment strategies were continuously refined based on participants' feedback. We began with group presentations at communitybased centers that offered a shared space for questions, concerns, and perspectives among peers. We eventually expanded our recruitment strategy to include digital media, table-based presentations at community spaces, letters, 
phone calls to clinic patients, and word of mouth. Each approach had its own strengths, but the key to successful enrollment was obtaining personal connections that were based on trust.

\section{Interpretation of Results}

\section{Encourage Co-Learning Between Academicians and Communities}

The CBPR process facilitated co-learning between academic and community partners while maintaining a balance of power. One example was how we interpreted the underlying mechanisms of increasing obesity in the U.S. Although increased rates of obesity among immigrants and refugees has been partly attributed to dietary acculturation (Antecol \& Bedard, 2006; Mulasi-Pokhriyal et al., 2012; C. Smith \& Franzen-Castle, 2012) members of the Hmong and Karen communities explained that their lived experiences did not support these findings, as people had seemingly continued to eat their traditional diet. Our study showed that caloric intake was similar between Hmong and Karen groups in Thailand and the U.S. (Vangay et al., 2018), and that diet accounted for only $16 \%$ of gut microbiome variation. Hence, our research findings support the communities' lived experiences, and highlight the importance of incorporating community perspectives into research interpretations.

Furthermore, analyzing dietary data presented some challenges, as many Hmong and Karen cultural foods were not easily identifiable in U.S.-based food databases. To ensure that the richness of the dietary data was fully captured, community researchers conducted a multiple pass 24-hour dietary recall (Gibson et al., 2017) in the participant's preferred language and translated the information into English if needed. Academic researchers then checked the foods against an existing U.S.-based food database, and if missing, manually curated a custom food database for analysis. The sheer number of missing foods was one of several reasons that led academic researchers to develop a new method for analyzing dietary data with the microbiome data, which ultimately ensured that all reported cultural foods were accounted for (Johnson et al., 2019). Accounting for the cultural foods was important for the community, and it enabled academic researchers to more accurately analyze the diet-microbiome associations, which could not have been accomplished without co-learning with the community researchers.

\section{Acknowledge that Results Could Implicate Individual Behavior and Thus Result in Experience of Shame}

The environment has been shown to play a larger role than genetics in shaping the gut microbiome (Rothschild et al., 2018). While diet is known as an important driver of gut microbiome composition (David et al., 2014; Muegge et al., 2011; Wu et al., 2011), we found that our participants' gut microbiomes "Americanized" at a faster rate than their diets did. Both Hmong and Karen CABs reflected that diet and exercise is not always a "personal choice," as they have access to fewer cultural foods and fewer opportunities for physical activity in the U.S. We strove to avoid intimating that Hmong 
and Karen's health outcomes are related to personal "choices" and instead highlighted the benefits of their traditional foods and practices, which can be seen through our dissemination activities below.

\section{Dissemination}

\section{Acknowledge That Defining "Action" is an Iterative Process}

While the study was designed with the intent to inform action, our research results could not clearly define actions to improve gut microbiome health. The academic-community partnership redefined "creating action" to include building a foundation of knowledge about the gut microbiome (an unfamiliar topic for Hmong and Karen community members), and stressing known diet strategies that could strengthen the gut microbiome. We started to build knowledge about the gut microbiome during recruitment by asking $\mathrm{CAB}$ members to identify concepts of overall health and "gut health" in their respective communities. We then integrated science and nutrition education during dissemination processes with the concept of maintaining traditions that support gut health through dissemination pamphlets, presentations, and videos. These materials made recommendations specifically to benefit gut microbiota (i.e. dietary fiber and fermented foods), while reinforcing the known benefits of consuming fruits and vegetables. Both Hmong and Karen community researchers and $\mathrm{CAB}$ members reflected that translating research into action takes time and cannot be rushed.

“That's research, sometimes the action doesn't come until after the results... we could let it happen organically. We don't always have to rush to deliver that action." (Hmong CAB Member)

\section{Design Dissemination Strategies Together with the Community}

We used an iterative strategy to create communication materials that emphasized images, narratives, and analogies over written explanations. This iterative process was essential in making dissemination meaningful for participants while adhering to scientific accuracy.

The two communities had different preferences for how our study results should be disseminated. The Hmong community researcher and $\mathrm{CAB}$ members reflected that while the written mailings were acceptable, they had a stronger preference for communication via social media. The Karen community researcher and $\mathrm{CAB}$ members stated that the animated videos and in-person engagement were more effective than the mailings, and also recommended more education on the new concepts of bacteria and the microbiome. As a result, our dissemination strategies included: illustrated pamphlets in English, Hmong, and Karen mailed to all participants; animated videos in each language distributed via social media and YouTube as well as physical USB drives; a central website about study results; and in-person workshops tailored for the two communities (https://www.knightslab.org/ immigrant-microbiome-proj). We partnered with local organizations to conduct workshops for each community based on research results combined 
with skill-building exercises, per each community's request. Hmong community members identified traditional practices, like farming and diets based on fresh vegetables, as a strength. Thus, we designed workshops for the Hmong community to support and encourage innovative Hmong farming practices and traditional Hmong cooking, which is primarily plant-based. The Karen $\mathrm{CAB}$ revealed that many Karen needed basic nutrition education for navigating U.S. grocery stores and kitchens before recommending actions for gut health. Thus, we partnered with the UMN Extension program to tailor a series of nutrition and cooking workshops for the Karen community. While the workshops were designed to address each community's needs, we used them as a platform to introduce the concept of the gut microbiome and to share our research study results.

\section{Allow Flexibility for Long-Term Commitments to On-Going Partnerships and CBPR Projects}

The academic-community research team repeatedly expressed their desire for a long-term partnership to advance science and benefit the communities. Although the project took place over five years, was limited by research practices (e.g. grant timelines, graduate student program), and CAB membership changed over time, the academic-community research team and $\mathrm{CAB}$ members expressed a desire to continue the discussion of next steps. Indeed, subsequent funds are leading to additional research projects with the Hmong and Karen communities.

\section{Discussion}

The IMP successfully partnered academics with community members to conduct, analyze, and disseminate gut microbiome results from a microbiome research study of Hmong and Karen communities in Minnesota and Thailand. The CBPR process helped to foster egalitarian partnerships and to enable a credible and trustworthy study that invited community participants to overcome their concerns and discomforts, such as collecting stool and sharing personal data. CBPR improved the efficiency and practicality of our project, through narrowing the research sample population and adjusting the intervention design to fit with community interests. Without those adjustments, the study may not have been feasible and could have caused harm and contributed to distrust. Finally, CBPR principles allowed us to prioritize the dissemination process and tailor materials for the Hmong and Karen communities. Improvements to recruitment and participation, research quality, and dissemination quality are all frequently described outcomes of CBPR studies (Jagosh et al., 2012; Viswanathan et al., 2004).

Efforts to include diverse populations in human microbiome studies have been limited but include citizen science projects (Bik et al., 2014; Gilbert et al., 2014; McDonald et al., 2018), community-based projects (Sankaranarayanan et al., 2015; Smits et al., 2017), clinical projects (Fettweis et al., 2014; Mondal et al., 2012; M. I. Smith et al., 2013; Subramanian et al., 2014), and targeted cohort studies (Fu et al., 2019; Kolonel et al., 2000). To our knowledge, only 
one other microbiome study has used a CBPR approach (Obregon-Tito et al., 2015), which underscores the need for fostering this practice in microbiome research.

The IMP illustrates how CBPR can be a useful approach for conducting microbiome research studies with refugee populations and to support efforts to make microbiome research more inclusive and equitable. Our findings demonstrate that in addition to improving the validity and efficacy of research projects, CBPR can be a tool to create respectful partnerships, build trust between community members and researchers, and ensure that research results are returned to the community as actionable items that can improve health.

\section{Acknowledgements}

The authors thank the members of the Hmong and Karen communities who volunteered their time in participating in or providing important feedback for this project. We especially thank members of our community advisory boards who contributed to this paper: Yoha Christianson, Duachi Her, Yeng Moua, Houa Vue-Her, and Pakou Xiong. We also thank Pimpanitta Saenyakul, who contributed to recruitment as a member of the academicresearch team. 


\section{References}

Antecol, H., \& Bedard, K. (2006). Unhealthy assimilation: Why do immigrants converge to American health status levels? Demography, 43(2), 337-360. http://www.ncbi.nlm.nih.gov/pubmed/ $\underline{16889132}$

Arcan, C., Larson, N., Bauer, K., Berge, J., Story, M., \& Neumark-Sztainer, D. (2014). Dietary and weight-related behaviors and body mass index among Hispanic, Hmong, Somali, and white adolescents. Journal of the Academy of Nutrition and Dietetics, 114(3), 375-383. https://doi.org/ 10.1016/j.jand.2013.11.019

Barcenas, C. H., Wilkinson, A. V., Strom, S. S., Cao, Y., Saunders, K. C., Mahabir, S., HernándezValero, M. A., Forman, M. R., Spitz, M. R., \& Bondy, M. L. (2007). Birthplace, years of residence in the United States, and obesity among Mexican-American adults. Obesity, 15(4), 1043-1052. https://doi.org/10.1038/oby.2007.537

Bates, L. M., Acevedo-Garcia, D., Alegría, M., \& Krieger, N. (2008). Immigration and generational trends in body mass index and obesity in the United States: Results of the National Latino and Asian American Survey, 2002-2003. American Journal of Public Health, 98(1), 70-77. https://doi.org/10.2105/ajph.2006.102814

B.E.R. Group \& Friedrich-Naumann-Stiftung. (1998). Forgotten victims of a bidden war: Internally displaced Karen in Burma. Burma Ethnic Research Group and Friedrich Naumann Foundation.

Bik, H. M., Coil, D. A., \& Eisen, J. A. (2014). microBEnet: Lessons learned from building an interdisciplinary scientific community in the online sphere. PLoS Biology, 12(6), e1001884. https://doi.org/10.1371/journal.pbio.1001884

Buseh, A. G., Underwood, S. M., Stevens, P. E., Townsend, L., \& Kelber, S. T. (2013). Black African immigrant community leaders' views on participation in genomics research and DNA biobanking. Nursing Outlook, 61(4), 196-204. https://doi.org/10.1016/j.outlook.2012.10.004

Cairney, J., \& Østbye, T. (1999). Time since immigration and excess body weight. Canadian Journal of Public Health Revue Canadienne de Sante Publique, 90(2), 120-124. https://doi.org/10.1007/ bf03404114

Careyva, B., LaNoue, M., Bangura, M., de la Paz, A., Gee, A., Patel, N., \& Mills, G. (2015). The effect of living in the United States on body mass index in refugee patients. Journal of Health Care for the Poor and Underserved, 26(2), 421-430. https://doi.org/10.1353/hpu.2015.0046

Claw, K. G., Anderson, M. Z., Begay, R. L., Tsosie, K. S., Fox, K., Garrison, N. A., \& Summer internship for INdigenous peoples in Genomics (SING) Consortium. (2018). A framework for enhancing ethical genomic research with Indigenous communities. Nature Communications, 9(1), 2957. https://doi.org/10.1038/s41467-018-05188-3

David, L. A., Maurice, C. F., Carmody, R. N., Gootenberg, D. B., Button, J. E., Wolfe, B. E., Ling, A. V., Devlin, A. S., Varma, Y., Fischbach, M. A., Biddinger, S. B., Dutton, R. J., \& Turnbaugh, P. J. (2014). Diet rapidly and reproducibly alters the human gut microbiome. Nature, 505(7484), 559-563. https://doi.org/10.1038/nature12820

Dawson-Hahn, E., Pak-Gorstein, S., Matheson, J., Zhou, C., Yun, K., Scott, K., Payton, C., Stein, E., Holland, A., Grow, H. M., \& Mendoza, J. A. (2016). Growth Trajectories of Refugee and Nonrefugee Children in the United States. Pediatrics, 138(6). https://doi.org/10.1542/ peds.2016-0953

Department of Economic and Social Affairs, Population Division. (2017). International Migration Report 2017 (No. ST/ESA/SER.A/403). United Nations. 
Ernst, E. (2002). Herbal medicinal products during pregnancy: Are they safe? BJOG: An International Journal of Obstetrics and Gynaecology, 109(3), 227-235. https://doi.org/10.1111/ j.1471-0528.2002.t01-1-01009.x

Fettweis, J. M., Brooks, J. P., Serrano, M. G., Sheth, N. U., Girerd, P. H., Edwards, D. J., Strauss, J. F., Jefferson, K. K., Buck, G. A., \& the Vaginal Microbiome Consortium. (2014). Differences in vaginal microbiome in African American women versus women of European ancestry. Microbiology, 160(10), 2272-2282. https://doi.org/10.1099/mic.0.081034-0

Fragiadakis, G. K., Smits, S. A., Sonnenburg, E. D., Van Treuren, W., Reid, G., Knight, R., Manjurano, A., Changalucha, J., Dominguez-Bello, M. G., Leach, J., \& Sonnenburg, J. L. (2019). Links between environment, diet, and the hunter-gatherer microbiome. Gut Microbes, 10(2), 216-227. https://doi.org/10.1080/19490976.2018.1494103

Franzen, L., \& Smith, C. (2009). Acculturation and environmental change impacts dietary habits among adult Hmong. Appetite, 52(1), 173-183. https://doi.org/10.1016/j.appet.2008.09.012

Fu, B. C., Randolph, T. W., Lim, U., Monroe, K. R., Cheng, I., Wilkens, L. R., Le Marchand, L., Lampe, J. W., \& Hullar, M. A. J. (2019). Temporal Variability and Stability of the Fecal Microbiome: The Multiethnic Cohort Study. Cancer Epidemiology Biomarkers Ev Prevention, 28(1), 154-162. https://doi.org/10.1158/1055-9965.epi-18-0348

Gibson, R. S., Charrondiere, U. R., \& Bell, W. (2017). Measurement Errors in Dietary Assessment Using Self-Reported 24-Hour Recalls in Low-Income Countries and Strategies for Their Prevention. Advances in Nutrition, 8(6), 980-991. https://doi.org/10.3945/an.117.016980

Gilbert, J. A., Jansson, J. K., \& Knight, R. (2014). The Earth Microbiome project: Successes and aspirations. BMC Biology, 12(1), 12915-12014. https://doi.org/10.1186/s12915-014-0069-1

Goel, M. S., McCarthy, E. P., Phillips, R. S., \& Wee, C. C. (2004). Obesity among U.S. immigrant subgroups by duration of residence.JAMA, 292(23), 2860-2867. https://doi.org/10.1001/ jama.292.23.2860

Heney, J. H., Dimock, C. C., Friedman, J. F., \& Lewis, C. (2014). Pediatric refugees in Rhode Island: Increases in BMI percentile, overweight, and obesity following resettlement. Rhode Island Medical Journal, 98(1), 43-47. https://www.ncbi.nlm.nih.gov/pubmed/25562061

Hervey, K., Vargas, D., Klesges, L., Fischer, P. R., Trippel, S., \& Juhn, Y. J. (2009). Overweight among refugee children after arrival in the United States. Journal of Health Care for the Poor and Underserved, 20(1), 246-256. https://doi.org/10.1353/hpu.0.0118

Himes, J. H., Story, M., Czaplinski, K., \& Dahlberg-Luby, E. (1992). Indications of early obesity in low-income Hmong children. American Journal of Diseases of Children, 146(1), 67-69. http://www.ncbi.nlm.nih.gov/pubmed/1736651

Israel, B. A., Coombe, C. M., Cheezum, R. R., Schulz, A. J., McGranaghan, R. J., Lichtenstein, R., Reyes, A. G., Clement, J., \& Burris, A. (2010). Community-based participatory research: A capacity-building approach for policy advocacy aimed at eliminating health disparities. American Journal of Public Health, 100(11), 2094-2102. https://doi.org/10.2105/ajph.2009.170506

Jacobsen, K., \& Landau, L. B. (2003). The dual imperative in refugee research: Some methodological and ethical considerations in social science research on forced migration. Disasters, 27(3), 185-206. https://doi.org/10.1111/1467-7717.00228

Jagosh, J., Macaulay, A. C., Pluye, P., Salsberg, J., Bush, P. L., Henderson, J., Sirett, E., Wong, G., Cargo, M., Herbert, C. P., Seifer, S. D., Green, L. W., \& Greenhalgh, T. (2012). Uncovering the benefits of participatory research: Implications of a realist review for health research and practice. Milbank Quarterly, 90(2), 311-346. https://doi.org/10.1111/j.1468-0009.2012.00665.x 
Johnson, A. J., Vangay, P., Al-Ghalith, G. A., Hillmann, B. M., Ward, T. L., Shields-Cutler, R. R., Kim, A. D., Shmagel, A. K., Syed, A. N., Personalized Microbiome Class Students, Walter, J., Menon, R., Koecher, K., \& Knights, D. (2019). Daily Sampling Reveals Personalized DietMicrobiome Associations in Humans. Cell Host $\sigma^{2}$ Microbe, 25(6), 789-802.e5. https://doi.org/ 10.1016/j.chom.2019.05.005

Kaplan, M. S., Huguet, N., Newsom, J. T., \& McFarland, B. H. (2004). The association between length of residence and obesity among Hispanic immigrants. American Journal of Preventive Medicine, 27(4), 323-326. https://doi.org/10.1016/j.amepre.2004.07.005

Kolonel, L. N., Henderson, B. E., Hankin, J. H., Nomura, A. M. Y., Wilkens, L. R., Pike, M. C., Stram, D. O., Monroe, K. R., Earle, M. E., \& Nagamine, F. S. (2000). A multiethnic cohort in Hawaii and Los Angeles: Baseline characteristics. American Journal of Epidemiology, 151(4), 346-357. https://doi.org/10.1093/oxfordjournals.aje.a010213

Koumpilova, M. (2015, December 29). Minnesota prepares to receive more refugees in 2016. Star Tribune. http://www.startribune.com/minnesota-is-gearing-up-to-receive-more-refugees-in-2016/ $\underline{363692201 /}$

Kuroiwa, Y., \& Verkuyten, M. (2008). Narratives and the constitution of a common identity: The Karen in Burma. Identities, 15(4), 391-412. https://doi.org/10.1080/10702890802201685

Lauderdale, D. S., \& Rathouz, P. J. (2000). Body mass index in a U.S. national sample of Asian Americans: Effects of nativity, years since immigration and socioeconomic status. International Journal of Obesity and Related Metabolic Disorders: Journal of the International Association for the Study of Obesity, 24(9), 1188-1194. http://www.ncbi.nlm.nih.gov/pubmed/11033989

Leung, M. W., Yen, I. H., \& Minkler, M. (2004). Community based participatory research: A promising approach for increasing epidemiology's relevance in the 21 st century. International Journal of Epidemiology, 33(3), 499-506. https://doi.org/10.1093/ije/dyh010

McDonald, D., Hyde, E., Debelius, J. W., Morton, J. T., Gonzalez, A., Ackermann, G., Aksenov, A. A., Behsaz, B., Brennan, C., Chen, Y., DeRight Goldasich, L., Dorrestein, P. C., Dunn, R. R., Fahimipour, A. K., Gaffney, J., Gilbert, J. A., Gogul, G., Green, J. L., Hugenholtz, P., ... Knight, R. (2018). American Gut: An Open Platform for Citizen Science Microbiome Research. MSystems, 3(3). https://doi.org/10.1128/msystems.00031-18

Michaud, J., \& Hamilton-Merritt, J. (1994). Tragic Mountains: The Hmong, the Americans, and the Secret Wars for Laos, 1942-1992. Pacific Affairs, 67(2), 314. https://doi.org/10.2307/2759454

Mondal, D., Minak, J., Alam, M., Liu, Y., Dai, J., Korpe, P., Liu, L., Haque, R., \& Petri, W. A. (2012). Contribution of enteric infection, altered intestinal barrier function, and maternal malnutrition to infant malnutrition in Bangladesh. Clinical Infectious Diseases, 54(2), 185-192. https://doi.org/ $\underline{10.1093 / \mathrm{cid} / \mathrm{cir} 807}$

Mossaad, N. (2019). Annual Flow Report, Refugees and Asylees: 2017. U.S. Department of Homeland Security.

Muegge, B. D., Kuczynski, J., Knights, D., Clemente, J. C., González, A., Fontana, L., Henrissat, B., Knight, R., \& Gordon, J. I. (2011). Diet drives convergence in gut microbiome functions across mammalian phylogeny and within humans. Science, 332(6032), 970-974. https://doi.org/10.1126/ science. 1198719

Mulasi-Pokhriyal, U., Smith, C., \& Franzen-Castle, L. (2012). Investigating dietary acculturation and intake among US-born and Thailand/Laos-born Hmong-American children aged 9-18 years. Public Health Nutrition, 15(1), 176-185. https://doi.org/10.1017/s1368980011001649

Murray, K. E., Davidson, G. R., \& Schweitzer, R. D. (2010). Review of refugee mental health interventions following resettlement: Best practices and recommendations. American Journal of Orthopsychiatry, 80(4), 576-585. https://doi.org/10.1111/j.1939-0025.2010.01062.x 
Obregon-Tito, A. J., Tito, R. Y., Metcalf, J., Sankaranarayanan, K., Clemente, J. C., Ursell, L. K., Zech Xu, Z., Van Treuren, W., Knight, R., Gaffney, P. M., Spicer, P., Lawson, P., Marin-Reyes, L., Trujillo-Villarroel, O., Foster, M., Guija-Poma, E., Troncoso-Corzo, L., Warinner, C., Ozga, A. T., \& Lewis, C. M. (2015). Subsistence strategies in traditional societies distinguish gut microbiomes. Nature Communications, 6(1), 6505. https://doi.org/10.1038/ncomms7505

Office of Academic Clinical Affairs. (2018). University of Minnesota Research Partnership Checklist. University of Minnesota Clinical and Translational Science Institute. https://www.ctsi.umn.edu/ sites/ctsi.umn.edu/files/research_partnership_checklist.pdf

Pfeifer, M. E., Sullivan, J., Yang, K., \& Yang, W. (2012). Hmong population and demographic trends in the 2010 Census and 2010 American Community Survey. Hmong Studies Journal, 13(2), 1. https://69.32.208.13/library/journal/1P3-2887149941/hmong-population-and-demographictrends-in-the-2010

Rothschild, D., Weissbrod, O., Barkan, E., Kurilshikov, A., Korem, T., Zeevi, D., Costea, P. I., Godneva, A., Kalka, I. N., Bar, N., Shilo, S., Lador, D., Vila, A. V., Zmora, N., Pevsner-Fischer, M., Israeli, D., Kosower, N., Malka, G., Wolf, B. C., ... Segal, E. (2018). Environment dominates over host genetics in shaping human gut microbiota. Nature, 555(7695), 210-215. https://doi.org/ $10.1038 /$ nature 25973

Sankaranarayanan, K., Ozga, A. T., Warinner, C., Tito, R. Y., Obregon-Tito, A. J., Xu, J., Gaffney, P. M., Jervis, L. L., Cox, D., Stephens, L., Foster, M., Tallbull, G., Spicer, P., \& Lewis, C. M. (2015). Gut Microbiome Diversity among Cheyenne and Arapaho Individuals from Western Oklahoma. Current Biology, 25(24), 3161-3169. https://doi.org/10.1016/j.cub.2015.10.060

Skinner, H. G., Calancie, L., Vu, M. B., Garcia, B., DeMarco, M., Patterson, C., Ammerman, A., \& Schisler, J. C. (2015). Using community-based participatory research principles to develop more understandable recruitment and informed consent documents in genomic research. PloS One, 10(5), e0125466. https://doi.org/10.1371/journal.pone.0125466

Smith, C., \& Franzen-Castle, L. (2012). Dietary acculturation and body composition predict American Mmong children's blood pressure. American Journal of Human Biology, 24(5), 666-674. https://doi.org/10.1002/ajhb.22295

Smith, M. I., Yatsunenko, T., Manary, M. J., Trehan, I., Mkakosya, R., Cheng, J., Kau, A. L., Rich, S. S., Concannon, P., Mychaleckyj, J. C., Liu, J., Houpt, E., Li, J. V., Holmes, E., Nicholson, J., Knights, D., Ursell, L. K., Knight, R., \& Gordon, J. I. (2013). Gut microbiomes of Malawian twin pairs discordant for kwashiorkor. Science, 339(6119), 548-554. https://doi.org/10.1126/ science. 1229000

Smits, S. A., Leach, J., Sonnenburg, E. D., Gonzalez, C. G., Lichtman, J. S., Reid, G., Knight, R., Manjurano, A., Changalucha, J., Elias, J. E., Dominguez-Bello, M. G., \& Sonnenburg, J. L. (2017). Seasonal cycling in the gut microbiome of the Hadza hunter-gatherers of Tanzania. Science, 357(6353), 802-806. https://doi.org/10.1126/science.aan 4834

SoLaHmo Partnership for Health \& Wellness at West Side Community Health Services, Inc. \& University of Minnesota's Program in Health Disparities Research Advisory Board. (2017). Community Based Participatory Action Research Partnership Protocol (Version 9/22/2017). University of Minnesota. https://z.umn.edu/partnershipprotocol

Subramanian, S., Huq, S., Yatsunenko, T., Haque, R., Mahfuz, M., Alam, M. A., Benezra, A., DeStefano, J., Meier, M. F., Muegge, B. D., Barratt, M. J., VanArendonk, L. G., Zhang, Q., Province, M. A., Petri, W. A., Jr., Ahmed, T., \& Gordon, J. I. (2014). Persistent gut microbiota immaturity in malnourished Bangladeshi children. Nature, 510(7505), 417-421. https://doi.org/ $10.1038 /$ nature 13421 
Temple, B., \& Moran, R. (2006). Doing Research with Refugees: Issues and Guidelines. Policy Press. https:/play.google.com/store/books/details?id=7941DwAAQBAJ

The Border Consortium. (n.d.). Brief History of the Border. History. Retrieved August 2019, from https://www.theborderconsortium.org/about-us/history/

The Border Consortium. (2018). Refugee Camp Populations: December 2018.

Tuck, E., \& Yang, K. W. (2014). R-words: Refusing research. In Humanizing Researcb: Decolonizing Qualitative Inquiry with Youth and Communities (pp. 223-248). https://methods.sagepub.com/ base/download/BookChapter/humanizing-research-decolonizing-qualitative-inquiry-with-youthcommunities/i798.xml

U.S. Department of Homeland Security. (2011). Yearbook of Immigration Statistics: 2010. U.S. Government Printing Office. https://www.dhs.gov/sites/default/files/publications/ Yearbook_Immigration_Statistics_2010.pdf

Vangay, P., Johnson, A. J., Ward, T. L., Al-Ghalith, G. A., Shields-Cutler, R. R., Hillmann, B. M., Lucas, S. K., Beura, L. K., Thompson, E. A., Till, L. M., Batres, R., Paw, B., Pergament, S. L., Saenyakul, P., Xiong, M., Kim, A. D., Kim, G., Masopust, D., Martens, E. C., ... Knights, D. (2018). US Immigration Westernizes the Human Gut Microbiome. Cell, 75(4), 962-972. https://doi.org/10.1016/j.cell.2018.10.029

Viswanathan, M., Ammerman, A., Eng, E., Garlehner, G., Lohr, K. N., Griffith, D., Rhodes, S., Samuel-Hodge, C., Maty, S., Lux, L., Webb, L., Sutton, S. F., Swinson, T., Jackman, A., \& Whitener, L. (2004). Community-based participatory research: Assessing the evidence. Evidence Report/Technology Assessment, 99, 1-8. https://www.ncbi.nlm.nih.gov/pubmed/15460504

Walker, P. F., Barnett, E. D., Hauck, F. R., \& Pearson, R. D. (2008). Immigrant Medicine. Emerging Infectious Diseases, 14(6), 1007-1008. https://doi.org/10.3201/eid1406.080154

Walton, M. J. (2008). Ethnicity, conflict, and history in Burma: The myths of Panglong. Asian Survey, 48(6), 889-910. https://as.ucpress.edu/content/48/6/889.abstract

Wu, G. D., Chen, J., Hoffmann, C., Bittinger, K., Chen, Y.-Y., Keilbaugh, S. A., Bewtra, M., Knights, D., Walters, W. A., Knight, R., Sinha, R., Gilroy, E., Gupta, K., Baldassano, R., Nessel, L., Li, H., Bushman, F. D., \& Lewis, J. D. (2011). Linking long-term dietary patterns with gut microbial enterotypes. Science, 334(6052), 105-108. https://doi.org/10.1126/science.1208344

Yatsunenko, T., Rey, F. E., Manary, M. J., Trehan, I., Dominguez-Bello, M. G., Contreras, M., Magris, M., Hidalgo, G., Baldassano, R. N., Anokhin, A. P., Heath, A. C., Warner, B., Reeder, J., Kuczynski, J., Caporaso, J. G., Lozupone, C. A., Lauber, C., Clemente, J. C., Knights, D., ... Gordon, J. I. (2012). Human gut microbiome viewed across age and geography. Nature, 486(7402), 222-227. https://doi.org/10.1038/nature11053 